\title{
Fenologia e prospecção fitoquímica do jaborandi (Pilocarpus microphyllus Stapf ex Holmes)
}

OLIVEIRA, C.S.A.'; LAMEIRA, O.A.2*; RIBEIRO, F.N.S.2; ROCHA, T.T.2; ASSIS, R.M.A. DE²

1 Universidade Federal Rural da Amazônia, UFRA, Av. Presidente Tancredo Neves, 2501, Bairro: Terra Firme, CEP: 66.077-830, Belém/PA. 'Embrapa Amazônia Oriental, Laboratório de Biotecnologia/ Horto de Plantas Medicinais CEP:66095-100, Belém/PA; *Autor para correspondência: osmar.lameira@embrapa.br

RESUMO: O estudo fenológico tem como finalidade determinar o ritmo sazonal dos eventos do ciclo de vida da planta, como floração e frutificação. Estes eventos são determinados por uma série de fatores, como: alternância de períodos chuvosos ou não chuvosos, intensidade da radiação solar, entre outros. A fitoquímica tem por objetivos conhecer os constituintes químicos de espécies vegetais ou avaliar sua presença. O presente trabalho teve como objetivo realizar a caracterização fenológica e a prospecção fitoquímica de folhas de jaborandi. A área de estudo para a avaliação do material vegetal foi o Banco Ativo de Germoplasma de Jaborandi da Embrapa Amazônia Oriental, situada no município de Belém-PA. Os acessos escolhidos foram: Merck, cultivado a pleno sol e à sombra; Japonês e Bonal 4, cultivados a pleno sol. Os registros foram realizados diariamente por um período de 28 meses correspondendo a agosto de 2010 a dezembro de 2012, de cinco plantas/acesso e organizados para demonstração mensal, através de fichas com a numeração respectiva das plantas, com registro de presença ou ausência das fenofases, floração e frutificação. A determinação do peso seco das amostras coletadas dos acessos foi realizada no Laboratório de Agroindústria da Embrapa Amazônia Oriental, onde, após a triagem e remoção das impurezas, as folhas foram cortadas, pesadas, colocadas em bandejas de inox e secas em estufa com circulação mecânica (FANEM 320-SE), à temperatura de $45^{\circ} \mathrm{C}$ por $120 \mathrm{~h}$. Em seguida, as amostras foram pesadas, trituradas e acondicionadas em sacos plásticos devidamente identificados e guardados sob refrigeração à temperatura de $10^{\circ}$ $\mathrm{C}$ até o uso. Os extratos das plantas foram preparados utilizando-se $100 \mathrm{~g}$ de folhas secas de cada acesso, triturados e submetidos à extração hidroalcoólica (etanol $80 \%$ ) em banho-maria sob refluxo, por aproximadamente 4 horas. Os extratos foram armazenados protegidos da luz na geladeira até o momento das análises. Foi analisada a presença das seguintes classes de substâncias químicas: ácidos orgânicos, açúcares redutores, polissacarídeos, proteínas e aminoácidos, taninos, catequinas, flavonoides, glicosídeos cardíacos, lactonas sesquiterpênicas, azulenos, carotenoides, esteroides e triterpenoides, depsídeos e depsidonas, derivados da cumarina, saponina espumídica, alcaloides, purinas, antraquinonas. Os resultados obtidos demonstraram que a espécie Pilocarpus microphyllus apresentou floração durante o ano todo e frutificação em onze meses, e a prospecção fitoquímica revelou a presença de 11 classes de constituintes químicos.

Palavras-chave: floração, frutificação, constituintes químicos.

\begin{abstract}
Phenology and phytochemical prospection of Jaborandi (Pilocarpus microphyllus Stapf ex Holmes). Phenological studies aim to determine the seasonal rhythm of the plant life cycle events, as flowering and fruiting. These events are determined by different factors, such as: alternating periods of rainy or dryer seasons, solar radiation intensity, among others. Phytochemistry aims to identify the chemical constituents of plant species or to evaluate their presence. This study aimed the phenological characterization and the phytochemical prospection of jaborandi leaves. The chosen study area for the plant material assessment was the Active Germplasm Bank of Jaborandi in the Embrapa Eastern Amazon, located in the city of Belém, PA, Brazil. The chosen accessions were the following: Merck, grown in full sun and in shade; Japanese and Bonal 4, both grown in full sun. Records were taken on a daily basis for a period of 28 months (August of 2010 to December of 2012), from five plants/accession,
\end{abstract}

Recebido para publicação em 06/08/2015

Aceito para publicação em 22/08/2016

10.1590/1983-084X/15_159

Rev. Bras. PI. Med., Campinas, v.18, n.2, supl. I, p.621-627, 2016. 
and arranged for monthly demonstrations by record sheets containing the corresponding plant numeration and the presence or absence of flowering and fruiting phenophases. The dry weight of the samples collected from the accessions was measured at the Laboratory of Agribusiness of Embrapa Eastern Amazon, where, after the sorting and removal of impurities, the leaves were cut, weighed, placed in stainless steel trays, and dried in forced air circulation oven (FANEM 320 UP) at a $45^{\circ} \mathrm{C}$ for $120 \mathrm{~h}$. Then, the samples were weighed, crushed, and placed in plastic bags properly identified and stored under refrigeration at a temperature of $10^{\circ} \mathrm{C}$ until the use. The plant extracts were prepared using $100 \mathrm{~g}$ of dried leaves from each accession, crushed, and subjected to hydroalcoholic extraction ( $80 \%$ ethanol) with water bath heating under reflux for approximately 4 hours. The extracts were stored protected from light in a refrigerator until the analysis. We analyzed the presence of the following classes of chemical substances: organic acids, reducing sugars, polysaccharides, proteins and amino acids, tannins, catechins, flavonoids, cardiac glycosides, sesquiterpene lactones, azulenes, carotenoids, steroids and triterpernoids, depsides and depsidones, coumarin derivatives, foam saponin, alkaloids, purines, anthraquinones. Our results showed that the flowering of Pilocarpus microphyllus occurred throughout the year and fruiting occurred in eleven months, and the phytochemical prospection revealed the presence of 11 classes of chemical constituents.

Keywords: flowering, fruiting, chemical constituents.

\section{INTRODUÇÃO}

O estudo fenológico tem como finalidade determinar o ritmo sazonal dos eventos do ciclo de vida, como floração e frutificação. Estes eventos são determinados por uma série de fatores, como alternância entre períodos chuvosos e não chuvosos e intensidade da radiação solar, entre outros (Silva, 1998).

De acordo com D'eça Neves \& Morellato (2004), para que o cultivo e o manejo das espécies vegetais sejam conduzidos de forma adequada, é essencial o entendimento da dinâmica dos ecossistemas onde essas espécies têm origem e desenvolvimento, sendo o estudo fenológico uma ferramenta essencial para tal finalidade. Além de permitir a compreensão da dinâmica das comunidades vegetais, o registro das características fenológicas é de grande importância por servir como indicador das respostas das plantas às condições climáticas e edáficas de determinada área (Fournier, 1974).

A organização biológica dos sistemas tropicais e sua evolução podem ser bem compreendidas através da análise fenológica de comunidades. A periodicidade nos padrões reprodutivos e vegetativos das plantas reflete a distribuição anual e a disponibilidade de tipos específicos de recursos (Frankie et al.1974). Informações sobre a fenologia das espécies amazônicas são ainda insuficientes e fragmentadas, e os dados existentes dizem respeito, principalmente, àquelas espécies de interesse ou potencial econômico.

A fitoquímica tem por objetivos conhecer os constituintes químicos de espécies vegetais ou avaliar sua presença, em estudos preliminares, é um indicador de grupos de metabólitos secundários relevantes à espécie em estudo (Falkenberg et al. 2010).

Em 1992, foi estabelecido um Banco Ativo de Germoplasma na Embrapa Amazônia Oriental em Belém, PA, visando à sua conservação e utilização em programas de melhoramento genético. Entretanto, pouco foi feito para se avaliar este germoplasma, o que impede o que impede, tanto a organização do banco, como o início de (Moura, et al. 2005).

Dentre os trabalhos de sazonalidade encontrados na literatura sobre jaborandi, Abreu et al. (2007) estudaram o perfil de alcaloides presentes em Pilocarpus microphyllus em diferentes estações e partes da planta e Taveira et al. (2003), verificaram a variação sazonal no óleo essencial de jaborandi. Quanto aos aspectos fenológicos da espécie, podemos citar os trabalhos preliminares de Rocha et al. (2011) que estudaram o período de floração e frutificação de jaborandi no Banco Ativo de Germoplasma da Embrapa Amazônia Oriental. Nesse sentido, o objetivo do presente estudo foi realizar a caracterização fenológica e a prospecção fitoquímica de folhas de jaborandi.

\section{MATERIAL E MÉTODOS}

As coletas foram realizadas no período de agosto de 2010 a dezembro de 2012. A área de estudo para a avaliação fenológica do material vegetal foi o Banco Ativo de Germoplasma de Jaborandi, instalado no horto de plantas medicinais da Embrapa Amazônia Oriental, situada no município

Rev. Bras. PI. Med., Campinas, v.18, n.2, supl. I, p.621-627, 2016. 
de Belém-PA, localizado a $1^{\circ} 27^{\prime} 21^{\prime \prime} \mathrm{S}$ de latitude e $48^{\circ} 30^{\prime} 14^{\prime \prime}$ W de longitude, com altitude de $10 \mathrm{~m}$ e temperatura média anual de $30^{\circ} \mathrm{C}$.

Os registros foram coletados de quatro acessos (Merck cultivado a pleno sol e à sombra natural, Japonês e Bonal 4 cultivados a pleno sol) diariamente por um período de 28 meses, correspondendo a agosto de 2010 a dezembro de 2012, de cinco plantas/acesso e organizados para demonstração mensal, através de fichas com a numeração respectiva das plantas, com registro de presença ou ausência das fenofases, floração e frutificação. O acesso Merck é procedente do município de Barra do Corda-MA e Japonês e Bonal 4, do município de Mojú-PA. Esses acessos apresentam teor de pilocarpina acima de 0,60\%, valor mínimo para ser considerado na seleção de um germoplasma (EMBRAPA, 1996).

O período de floração incluiu desde a formação dos botões até o final do período de antese das flores, e o de frutificação desde a formação visível dos frutos até sua queda. Os registros das fenofases dos indivíduos foram observados sem levar em consideração os fatores edáficos e bióticos.

A análise fitoquímica das amostras provenientes do acesso Merck cultivado a pleno sol e à sombra foi realizada no Laboratório de Agroindústria da Embrapa Amazônia Oriental. As folhas foram coletadas no mês de julho pela parte da manhã de ramos e em dias em que não estavam em período fértil conforme Lameira \& Amorim (2008). Após a triagem e remoção das impurezas, as folhas foram cortadas, pesadas, colocadas em bandejas de inox e secas em estufa com circulação mecânica (FANEM 320-SE), a temperatura de $45^{\circ} \mathrm{C}$ por $120 \mathrm{~h}$. Em seguida, as amostras foram pesadas, trituradas em moinho de faca e acondicionadas em sacos plásticos, devidamente identificadas e armazenadas sob, refrigeração a temperatura de $10^{\circ} \mathrm{C}$ até o uso.

Os extratos das plantas foram preparados utilizando-se $100 \mathrm{~g}$ de folhas secas de cada acesso, trituradas e submetidas a extração hidroalcoólica (etanol $80 \%$ ) em banho-maria sob refluxo por aproximadamente, 4 horas. O material foi, então, filtrado a vácuo e concentrado em evaporador rotatório (Buch El 131 Sibata) a 150 rpm sob pressão reduzida a $45^{\circ}$, acoplado a bomba de vácuo (AAKer). A seguir, foram armazenados protegidos da luz na geladeira até o momento das análises (Matos, 1997).

Os extratos foram submetidos a análise fitoquímica, segundo metodologia dos protocolos descritos por Matos (1997). Foi analisada a presença das seguintes classes de substâncias químicas: ácidos orgânicos, açúcares redutores, polissacarídeos, proteínas e aminoácidos, taninos, catequinas, flavonoides, glicosídeos cardíacos, lactonas sesquiterpênicas, azulenos, carotenoides, esteroidese triterpernoides, depsídeos e depsidonas, derivados da cumarina, saponina espumídica, alcaloides, purinas, antraquinonas. Os reagentes utilizados para os testes foram os mesmos citados por Harborne (1984), Matos (1997) e Falkenberg et al. (2010).

\section{RESULTADOS E DISCUSSÃO}

No sistema de cultivo a pleno sol do acesso Merck ocorreu floração e frutificação em todos os meses do período avaliado de agosto de 2010 a dezembro de 2012 (Figura 1). Nos meses de fevereiro, maio e novembro ocorreram as maiores médias de frequências de número de dias (21 dias) de floração e frutificação, favorecendo a coleta de sementes para a produção de mudas. Entretanto, o número de dias para a coleta de folhas visando a análise fitoquímica foi reduzido, haja visto que a coleta de folhas para a análise fitoquímica deve ser realizada, preferencialmente, quando os ramos da planta não estão em fase reprodutiva, devido ao fato da taxa de concentração dos metabólitos secundários se encontrar mais alta (Lameira \& Amorim, 2008). O menor número de dias de floração e frutificação foi registrado no mês de julho com 7 dias, nos 2 anos consecutivos, o que favoreceu a coleta de folhas para análise fitoquímica, reduzindo, no entanto, o número de dias para coleta de sementes visando a produção de mudas (Figura 1).

No acesso Merck cultivado a sombra (Figura 2), a floração no período avaliado ocorreu em todos os meses do ano, sendo a maior frequência registrada no mês de setembro, com 20 dias e, nos meses de fevereiro a maio e agosto e outubro, frequências de 19 dias. Os menores números de dias foram registradas nos meses de julho e dezembro, com 8 e 7 dias, respectivamente, nos 2 anos. A frutificação ocorreu em todos os meses do ano, exceto no mês de janeiro. O maior número de dias observado ocorreu nos meses de fevereiro, maio, setembro e novembro, com 21 dias. No mês de julho, ocorreu o menor número, com 8 dias de frutificação. As menores frequências de dias em que ocorrem as fenofases favoreceria a coleta de material vegetal para análise fitoquímica conforme Lameira \& Amorim (2008), porém prejudicaria a coleta de sementes para multiplicação da espécie.

No acesso Bonal 4 (Figura 3) a floração ocorreu em todos os meses do ano, sendo registrados 21 dias nos meses de janeiro, fevereiro, março e maio, e 22 dias no mês de novembro. Quanto a frutificação esta não ocorreu somente no mês de abril. No mês de novembro foi registrado o maior número de dias, com 22 dias, e, em fevereiro e maio, 21 dias. O menor número de dias de floração e

Rev. Bras. PI. Med., Campinas, v.18, n.2, supl. I, p.621-627, 2016. 


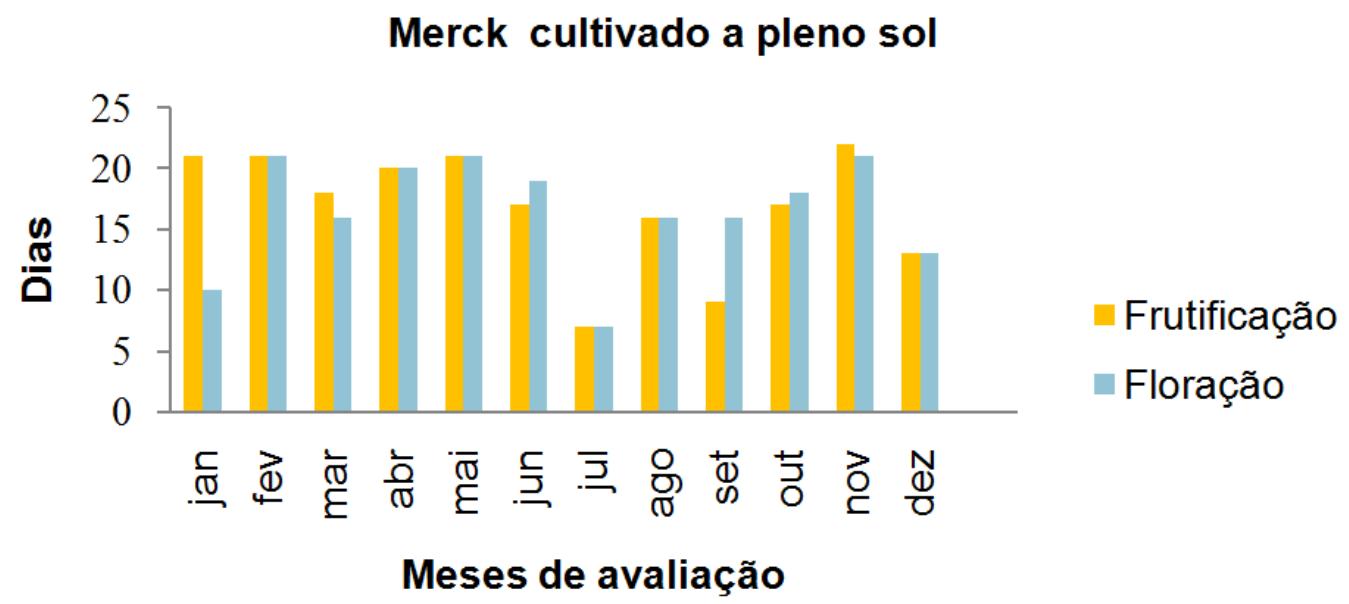

FIGURA 1. Média de dias de floração e frutificação do acesso Merck cultivado a pleno sol, no período de agosto de 2010 a dezembro de 2012.

\section{Merck cultivado à sombra}

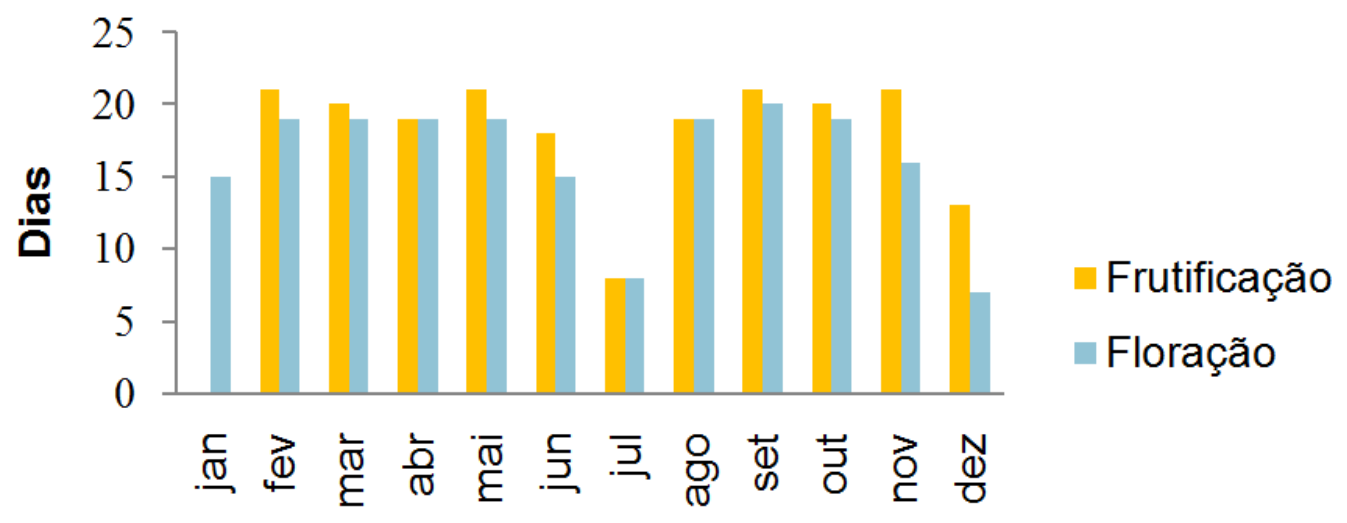

\section{Meses de avaliação}

FIGURA 2. Média de dias de floração e frutificação do acesso Merck cultivado à sombra, no período de agosto de 2010 a dezembro de 2012.

\section{Bonal 4}

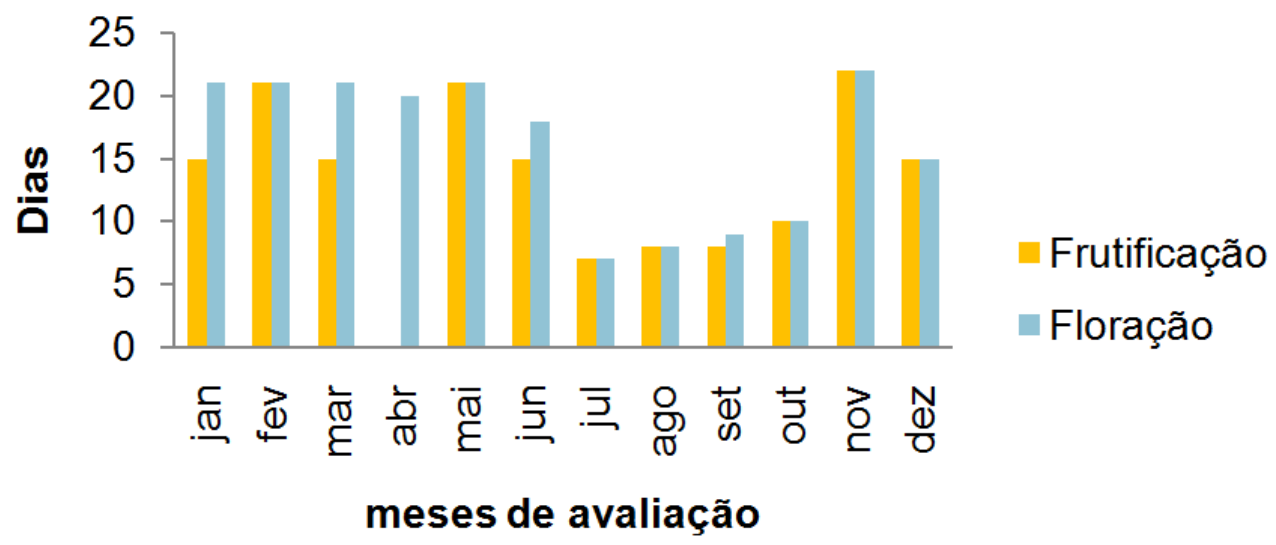

FIGURA 3. Média de dias de floração e frutificação do acesso Bonal 4 cultivado a pleno sol, no período de agosto de 2010 a dezembro de 2012. 


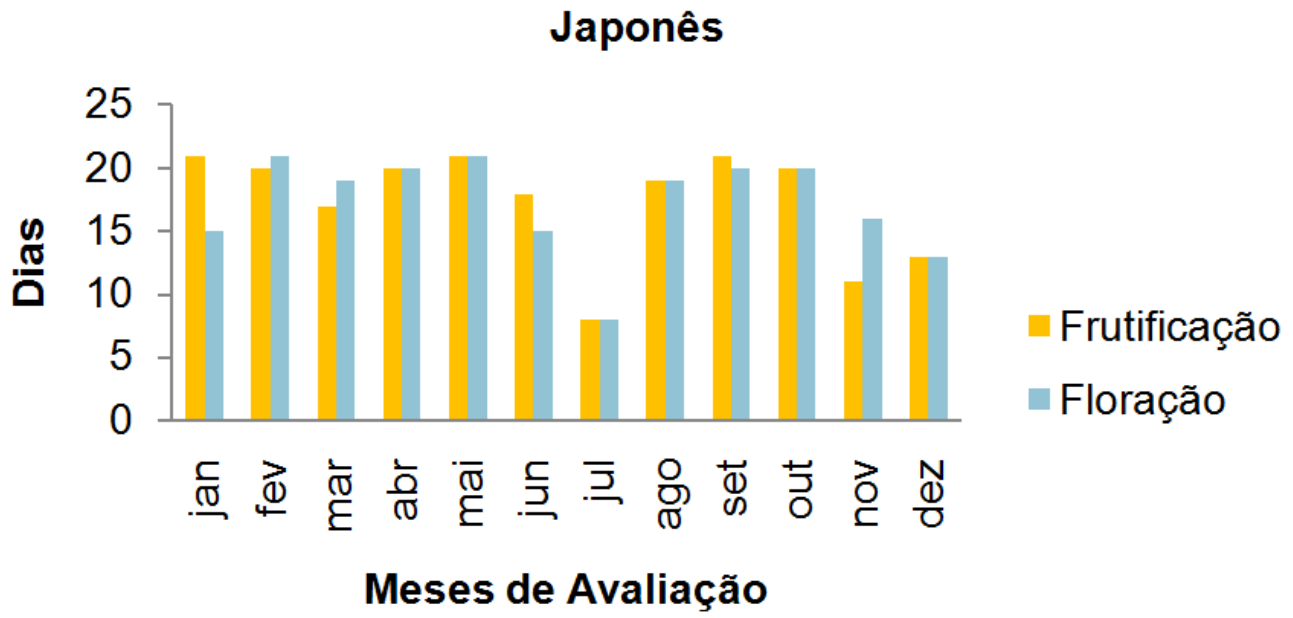

FIGURA 4. Média de dias de floração e frutificação do acesso Japonês cultivado a pleno sol, no período de agosto de 2010 a dezembro de 2012.

frutificação ocorreu no mês de julho, com 7 dias. Nos meses de janeiro, março, abril, junho e setembro, o número de dias com floração foram maiores que o de frutificação.

Para o acesso Japonês (Figura 4), a floração e frutificação ocorreu em todos os meses do ano. Nos meses de fevereiro e maio, foram registrados 21 dias de floração e nos meses de abril, setembro e outubro, 20 dias. Na frutificação, os maiores registros ocorreram nos meses de janeiro, maio e setembro, com 21 dias, e nos meses de fevereiro, abril e outubro, 20 dias. O menor registro para floração e frutificação ocorreu no mês de julho, com 7 dias, coincidindo com o início do período menos chuvoso na área de estudo.

Os resultados de fenologia obtidos neste trabalho demonstraram que a espécie Pilocarpus microphyllus, independente do acesso e do sistema de cultivo, apresentou floração durante todo o ano e frutificação em até onze meses, facilitando o processo de colheita de sementes para a produção de mudas e regeneração de novas plantas, bem como o manejo da espécie. Entretanto, os resultados obtidos demonstraram que a coleta de material vegetal, principalmente as folhas para análise fitoquímica e uso, deve ser bem planejada, porque, no período de floração e frutificação, as substâncias ativas se deslocam para os órgãos de reprodução, proporcionando uma maior concentração das mesmas (Lameira \& Amorim, 2008). Assim, as folhas coletadas poderiam estar com concentração muito baixa dessas substâncias, o que, consequentemente, prejudicaria o uso dessa parte do vegetal.

Na caracterização da fenologia do jaborandi conduzida por Rocha et. al (2011) por um período de 17 meses e no mesmo local do presente trabalho, os resultados obtidos foram similares aos da presente pesquisa. Os estudos fenológicos realizados estão de acordo com Araújo (1970) e Bencke \& Morellato (2002).

Através de estudos fenológicos, tornase possível conhecer a época de reprodução, a deciduidade e o ciclo de crescimento vegetativo das plantas, parâmetros que podem ser utilizados para o manejo adequado da flora (Ribeiro \& Castro, 1986). O conhecimento da fenologia é importante para poder ajudar no planejamento do manejo do plantio (Falcão et al. 2000).

De acordo com Silva (1998), um dos passos iniciais mais importantes para o conhecimento e utilização das espécies vegetais é o estudo da sua biologia, em particular o da fenologia. Nesse sentido, é de fundamental importância o conhecimento do período de floração e frutificação dessas espécies para a identificação do período mais apropriado para a colheita dos materiais a serem utilizados na agroindústria e na fitoquímica.

Muniz (2008) afirma que há um período grande de floração de abril a julho, com pico em novembro/dezembro em árvores da Amazônia Maranhense, justificado pelo início da estação chuvosa. Araújo (1970) considera que a floração e a frutificação ocorrem, na maioria dos casos, na dependência da distribuição das chuvas durante o ano, embora o efeito da regularidade ou severidade das estações seca ou chuvosa sobre as plantas permaneça desconhecido (Newstrom et al. 1994). Isso não ocorreu no presente trabalho com o jaborandi, pois, independente do acesso, do sistema de cultivo e do período de chuvas (maior período de ocorrência no município de Belém - PA de janeiro a junho e menor período de ocorrência de julho a dezembro), a floração ocorreu em todos os meses do ano e a frutificação em onze meses.

A prospecção fitoquímica realizada nas

Rev. Bras. PI. Med., Campinas, v.18, n.2, supl. I, p.621-627, 2016. 
TABELA 1. Prospecção fitoquímica de folhas de jaborandi (P. microphyllus), do acesso Merck, cultivado a pleno sol e à sombra.

\begin{tabular}{lcc}
\hline Prospecção Fitoquímica & Folhas (Cultivo a pleno sol) & Folhas (Cultivo à sombra) \\
\hline Ácidos orgânicos & $\mathrm{N}$ & $\mathrm{N}$ \\
Açúcares redutores 1 & $\mathrm{P}$ & $\mathrm{N}$ \\
Açúcares redutores 2 & $\mathrm{N}$ & $\mathrm{N}$ \\
Polissacarídeos & $\mathrm{N}$ & $\mathrm{P}$ \\
Proteínas e aminoácidos 1 & $\mathrm{P}$ & $\mathrm{P}$ \\
Taninos & $\mathrm{P}$ & $\mathrm{N}$ \\
Catequinas & $\mathrm{N}$ & $\mathrm{N}$ \\
Derivados da cumarina & $\mathrm{N}$ & $\mathrm{P}$ \\
Esteroides & $\mathrm{P}$ & $\mathrm{P}$ \\
Saponina espumídica & $\mathrm{N}$ & $\mathrm{P}$ \\
Alcaloides 1 & $\mathrm{P}$ & $\mathrm{P}$ \\
Alcaloides 2 & $\mathrm{P}$ & $\mathrm{P}$ \\
Alcaloides 3 & $\mathrm{P}$ & $\mathrm{P}$ \\
Alcaloides 4 & $\mathrm{P}$ & $\mathrm{N}$ \\
Purinas & $\mathrm{N}$ & $\mathrm{N}$ \\
Antraquinonas 1 & $\mathrm{~N}$ & $\mathrm{~N}$ \\
Antraquinonas 2 & $\mathrm{~N}$ & $\mathrm{P}$ \\
Depsídios e depsidonas & $\mathrm{P}$ &
\end{tabular}

$\mathrm{P}=$ positivo; $\mathrm{N}$ = negativo.

folhas de jaborandi do acesso Merck, cultivado a pleno sol e à sombra visando identificar a influência do sistema de cultivo, revelou a presença de 11 classes de constituintes químicos: açúcares redutores, proteínas e aminoácidos, taninos, azuleno, carotenoides, esteroides, triperpenoides, depsídeos, depsidonas, saponina espumídica e alcaloides 1, 2, 3 e 4. Dentre esses, foi observada a presença de açúcares redutores no cultivo a pleno sol e ausência no cultivo à sombra, bem como a presença de saponina espumídica no cultivo sombreado e sua ausência no cultivo a pleno sol, únicas diferenças qualitativas identificadas sob a influência dos sistemas de cultivos, não afetando a classe dos alcaloides, uma das substâncias mais importantes do jaborandi (Tabela 1).

As análises de prospecção fitoquímica de plantas medicinais são métodos laboratoriais, que têm por objetivo detectar as classes de constituintes químicos presentes na parte da planta usada na medicina popular (Paracampo, 2009).

A natureza química do vegetal é determinada pela presença ou não de determinadas substâncias, tais como os alcaloides e, dentre estes, destaca-se, no jaborandi, a pilocarpina, seu principal constituinte químico (Lameira \& Amorim, 2008). Nesse sentido, a determinação deste alcaloide é de fundamental importância para os programas de melhoramento genético. A determinação do teor de pilocarpina não foi realizada neste trabalho por essa informação já existir dentro do BAG jaborandi da Embrapa Amazônia Oriental, tendo sido realizado pela Japan International Cooperation Agency - JICA (EMBRAPA, 1996), tendo sido determinado que $86,6 \%$ dos acessos apresentam teor de pilocarpina acima de $0,60 \%$.

Em conclusão, os acessos estudados do Banco Ativo de Germoplasma de Jaborandi da Embrapa Amazônia Oriental apresentam floração em todos os meses do ano e frutificação durante onze meses. Na prospecção fitoquímica realizada nas folhas de jaborandi, 11 classes são identificadas independentes do sistema de cultivo realizado, a pleno sol ou à sombra. Dentre essas, nove classes são comuns aos dois sistemas e duas delas, açúcares redutores e saponina espumídica, exclusivas do sistema de cultivo a pleno sol e do cultivo à sombra, respectivamente.

\section{REFERÊNCIAS}

ABREU, I. N. et al. Characterization of the variation in the imidazole alkaloid profile of Pilocarpus microphyllus in diferente seasons and parts of the plant by electrospray ionization mass spectrometry fingerprinting and identification of novel alkaloids by tandem mass spectrometry. Rapid Communication in Mass

Rev. Bras. PI. Med., Campinas, v.18, n.2, supl. I, p.621-627, 2016. 
Spectrometry, v.21, p.1205-1213, 2007.

ARAÚJO, V.C. Fenologia de essências florestais amazônicas. Boletim do Instituto Nacional de Pesquisas da Amazônia, v.4, p.1-25, 1970.

BENCKE, C.S.C.; MORELLATO, L.P.C. Comparação de dois métodos de avaliação da fenologia de plantas, sua interpretação e representação. Revista Brasileira de Botânica, v.25, n.3, p.269-75, 2002.

D'EÇA-NEVES, F.F; MORELLATO, L.P.C. Métodos de amostragem e avaliação utilizados em estudos fenológicos de florestas tropicas. Acta Botanica Brasilica, v.18, n.1, p.99-108, 2004.

EMBRAPA. Centro de Pesquisa Agroflorestal da Amazônia Oriental (Belém,PA). Geração de tecnologia agroindustrial para o desenvolvimento do trópico úmido. Belém: EMBRAPA-CAPTU/JICA, 1996. p.305 (EMBRAPA - CAPATU. Documentos, 85).

FALCÃO, M.A. et al. Fenologia e produtividade do Araçá-boi (Eugenia stipitata, Myrtaceae) na Amazônia Central. Acta Amazônica, v.30, n.1, p.9-21, 2000.

FALKENBERG, M. DE B. et al. Introdução a analise fitoquímica. In: SIMÕES, C. M.O.(Ed). Farmacognosia: da planta ao medicamento. 2. ed. rev. - Porto Alegre. Editora da UFRGS; Florianopólis: Editora da UFSC, 2000. p.163-180.

FOURNIER, L.A. Un método cuantitativo para la medición de características fenológicas en árboles. Turrialba, v.24, p.422-423, 1974.

FRANKIE, FRANKIE, G.W. et al. Tropical plant phenology: applications for studies in community ecology. In: LIETH, $\mathrm{H}$. (Ed.). Phenology and seasonality modeling. 1.ed. New York: Springer-Verlag, 1974. p.287-96.

HARBORNE, J.B. Phytochemical methods: a guide to modern techniques of plant analysis, 2ed. Chapman and Hall, London, 1984, 288p.

LAMEIRA, O.A.; AMORIM, A.C.L. Substâncias ativas de plantas medicinais In: LAMEIRA, O.A.; PINTO, J.E.B.P. (Eds). Plantas medicinais: do cultivo, uso e manipulação à recomendação popular. 1.ed. Belém: Embrapa Amazônia Oriental, 2008. p.73-82.

MATOS, F.J.A. Introdução à Fitoquímica Experimental. 2.ed. Fortaleza: Editora UFC, 1997. 141p.

MOURA, E.F. et al. Genetic diversity of Pilocarpus microphyllus accessions using leaf traits. Crop Breeding and Applied Biotechnology, v.5, p.348354, 2005.

MUNIZ, F.H. Padrões de floração e frutificação de árvores da Amazônia Maranhense. Acta amazônica, v.38, n.4, p.617-26, 2008.

NEWSTROM, L.E. et al. Diversity of long-term flowering patterns. In: MCDADE, L.A. et al. (Eds.). La Selva: ecology and natural history of a neotropical rain forest. 1.ed. Chicago: Chicago University Press, 1994. p.142-60.

PARACAMPO, N.E.N.P. Prospecção fitoquímica de plantas medicinais. 1.ed. Belém: Embrapa Amazônia Oriental, 2009. 13p.

RIBEIRO, J.R.; CASTRO, L.H.R. Método quantitativo para avaliar características fenológicas em árvores. Revista Brasileira de Botânica, v.9, n.1, p.7-11, 1986.

ROCHA, T. T. et al. Avaliação do período de floração e frutificação do banco ativo de germoplasma do jaborandi. In: SEMINÁRIO DE INICIAÇÃO CIENTÍFICA DA EMBRAPA, 15, 2011, Belém. Anais.. Belém: Embrapa Amazônia Oriental, 2011. p.1-4.

SILVA, S.M.P. da. Arnica de Campos Rupestres Lychnophora pinaster Mart. Asteraceae: aspectos da fenologia e de aquênios. In: MING, L.C. (Ed.). Plantas Medicinais Aromáticas e Condimentares: avanços na pesquisa agronômica. 1.ed. Botucatu: UEP, 1998. p.1-18.

TAVEIRA, F. S. N. Seasonal variation in the essential oil of Pilocarpus microphyllus Stapf. Anais da Academia Brasileira de Ciências, v.75, n.1, p.27-31, 2003. 